\title{
INFLUÊNCIA DA ADIÇÃO DE SACAROSE NA ESTABILIDADE DA POLPA DE BACURI CONSERVADA POR MÉTODOS COMBINADOS
}

\author{
Influence of addition of sucrose in the stability of bacuri pulp \\ preservation by combined methods
}

\author{
Germania Almeida Souza Bezerra ${ }^{1}$, Geraldo Arraes $\mathrm{Maia}^{2}$, Raimundo Wilane de Figueiredo ${ }^{3}$, \\ Men de Sá Moreira de Souza Filho ${ }^{4}$, Paulo Henrique Machado de Sousa ${ }^{5}$
}

\begin{abstract}
RESUMO
O estudo do processo de conservação da polpa de bacuri (Platonia insignis Mart.), através da aplicação da tecnologia de obstáculos, foi feito pela combinação dos seguintes fatores: adição de benzoato de sódio (1000 ppm) e metabissulfito de sódio (400 $\mathrm{ppm})$, tratamento térmico $\left(100^{\circ} \mathrm{C} / 2 \mathrm{~min}\right.$.) e redução da atividade de água pela adição de sacarose $(0,17,4 \mathrm{e} 28,6 \%$ (p/p)). A estabilidade dos produtos foi avaliada segundo suas características físico-químicas, microbiológicas e sensoriais, a cada 30 dias, durante quatro meses de armazenamento, à temperatura ambiente $\left(25^{\circ} \mathrm{C} \pm 2^{\circ} \mathrm{C}\right)$. As características físico-químicas dos produtos obtidos sofreram pouca alteração durante o armazenamento, sendo os teores de açúcares redutores e o teor de dióxido de enxofre as características mais afetadas nos três produtos. Os resultados mostraram que os tipos de obstáculos usados e sua intensidade foram capazes de assegurar a estabilidade microbiológica e uma boa aceitação sensorial dos produtos durante o período de armazenamento.
\end{abstract}

Termos para indexação: Platonia insignis Mart., métodos combinados, alimentos auto-estáveis, estabilidade.

\begin{abstract}
The study of preservation process of the bacuri pulp (Platonia insignis Mart.) through the application of hurdle technology was done by the application of the following preservation factors: addition of sodium benzoate (1000 ppm) and sodium metabissulphite $(400 \mathrm{ppm})$, thermal treatment $\left(100^{\circ} \mathrm{C} / 2 \mathrm{~min}\right.$.) and reduction of the water activity by the addition of sucrose $(0,17,4$ and $28,6 \%$ (w/ w)). Stability was assessed monthly by means of physico-chemical, microbiological and sensorial methods, each 30 days, during four months of storage at room temperature $\left(25^{\circ} \mathrm{C} \pm 2^{\circ} \mathrm{C}\right)$. Physico-chemical characteristics of the products obtained little changed during the storage, being the reduced sugars and sulfite dioxide contents the most affected characteristics in three products. Results showed that the obstacles used and their intensities were capable to assure the microbiological stability and a good sensory acceptability of the products during the storage time.
\end{abstract}

Index terms: Platonia insignis Mart., combined methods, shelf stable foods, stability.

(Recebido para publicação em 26 de janeiro de 2005 e aprovado em 6 de março de 2006)

\section{INTRODUÇÃO}

Na Região Amazônica brasileira existem algumas espécies de fruteiras domesticadas ou cultivadas de grande potencial agroindustrial, ainda pouco exploradas. Dentre estas destaca-se o bacuri (Platonia insignis Mart.), por sua importância econômica nas regiões Norte e Nordeste (CLEMENT \& VENTURIERI, 1990; VILLACHICA, 1996). Apesar da grande oferta deste fruto nas regiões produtoras, poucas pesquisas têm se voltado para os aspectos tecnológicos e industriais deste fruto. $\mathrm{O}$ crescimento da demanda não é acompanhado pela geração e adaptação de tecnologias, que viabilizem a redução das perdas pós-colheita, o aumento na conservação dos frutos e na qualidade dos produtos. Segundo Fonderfru (1986), devido às dificuldades para a preservação de frutos "in situ", são geradas perdas que variam entre $10 \%$ e $40 \%$ na maioria dos países ibero-americanos.

A preservação de alimentos por métodos combinados, utilizando a tecnologia de obstáculos, consiste na combinação adequada de vários parâmetros ou barreiras, tais como tratamento térmico brando ou moderado, leve redução da atividade de água $(\mathrm{Aa})$, redução de $\mathrm{pH}$, adição simples ou combinada de agentes antimicrobianos, etc. Dessa forma obtêm-se alimentos estáveis à temperatura ambiente e com baixos custos de produção (ALZAMORA et al., 1993; CHIRIFE \& FAVETO, 1992; WELTI-CHANES

${ }^{1}$ Engenheira de Alimentos, Mestre, Universidade Federal do Ceará - Av. Mister Hull Alagadiço - Cx. P. 12168 - $60.356-000$ - Fortaleza, CE.

${ }^{2}$ Engenheiro Agrônomo, Ph.D., Universidade Federal do Ceará - Departamento de Tecnologia de Alimentos - Av. Mister Hull Alagadiço - Cx. P. 12168 60.356-000 - Fortaleza, CE.

${ }^{3}$ Engenheiro Agrônomo, Doutor, Universidade Federal do Ceará - Centro de Ciências Agrárias/CCA - Departamento de Tecnologia de Alimentos Av. Mister Hull Alagadiço - Cx. P. 12168 - 60.356-000 - Fortaleza, CE.

${ }^{4}$ Engenheiro Químico, Mestre - EMBRAPA - CE.

${ }^{5}$ Químico, Mestre - Universidade Federal de Viçosa/UFV - Av. P. H. Rolfs s/n - 36.570-000 - Viçosa, MG. 
et al., 1997). Este tipo de tecnologia é de simples aplicação, podendo ser utilizada como técnica alternativa à refrigeração, congelamento, desidratação e outros procedimentos que, geralmente, necessitam de alto investimento em equipamentos e ainda consomem muita energia (DAZA et al., 1997).

As características sensoriais e microbiológicas de frutos preservados por métodos combinados mantêm-se estáveis durante um período de quatro a oito meses, apresentando, de forma geral, uma boa aceitação relacionada ao sabor, aroma, cor e textura (ALZAMORA et al., 1993; LEISTNER, 1992). As polpas obtidas por métodos combinados podem ser utilizadas como matériaprima para a industrialização de sucos, néctares, cremes e outros.

Visou-se com presente trabalho avaliar a estabilidade da polpa de bacuri conservada por métodos combinados durante 120 dias de armazenamento à temperatura ambiente.

\section{MATERIAL E MÉTODOS}

Os frutos do bacurizeiro utilizados para o desenvolvimento do trabalho foram colhidos de matrizes no Estado do Piauí, fornecidos pela EMBRAPA - Centro Nacional de Pesquisa Agropecuária do Meio-Norte, em estádio comercial de maturação.

O benzoato de sódio de grau alimentício (98\%), fabricado por Liquid Química S.A., foi usado como conservante, e o metabissulfito de sódio (P.A.), da Vetec, como antioxidante. A sacarose, adquirida em mercado local, foi utilizada para a redução da atividade de água.

Os frutos foram selecionados, lavados em água clorada (50 ppm de cloro ativo/15 min.), descascados e cortados manualmente. A polpa do fruto in natura foi obtida por extração manual e para seu refinamento fez-se uso de um liquidificador industrial. A polpa foi submetida a um processo baseado na tecnologia dos métodos combinados, através da utilização dos seguintes obstáculos: adição de benzoato de sódio (1000ppm) e metabissulfito de sódio (400 ppm), tratamento térmico $\left(100^{\circ} \mathrm{C} / 2 \mathrm{~min}\right.$.) e redução da atividade de água pela adição de sacarose, através de diferentes concentrações: Controle (sem adição de sacarose), tratamento com 17,4\% (p/p) de sacarose e um tratamento com $28,6 \%$ (p/p) de sacarose, sendo estes valores selecionados a partir do estudo realizado por Bezerra et al. (2004), em que foi avaliada a redução da atividade de água para faixa de 0,90-0,99, através da adição de sacarose, para obtenção de alimentos auto- estáveis conservados por métodos combinados (AGUILERA \& CHIRIFE, 1994).

Os produtos obtidos foram acondicionados em embalagens flexíveis de polietileno com espessura de $25 \mathrm{~mm}$, termo-seladas, e armazenados à temperatura ambiente $\left(25^{\circ} \mathrm{C} \pm 2^{\circ} \mathrm{C}\right)$. A estabilidade dos produtos foi avaliada por meio de análises físico-químicas (atividade de água, $\mathrm{pH}$, acidez total titulável, sólidos solúveis totais, açúcares redutores, dióxido de enxofre total e cor), microbiológicas (contagens de microrganismos aeróbios mesófilos, bolores e leveduras, coliformes a $35^{\circ} \mathrm{C}$ e $45^{\circ} \mathrm{C}$, e Salmonella sp.) e sensorial (teste de aceitação global), a cada 30 dias, por um período de 120 dias. Foi tomada uma amostra de cada repetição de tratamentos para análise.

A atividade de água foi determinada em aparelho AQUALAB, modelo CX2 (Decagon Devices Inc.). $\mathrm{O}$ pH foi medido em potenciômetro HANNA INSTRUMENTS, modelo HI 9321 , a $25^{\circ} \mathrm{C}$. A determinação da acidez total titulável foi feita de acordo com a metodologia do Instituto Adolfo Lutz (1985). Os açúcares redutores foram determinados pelo método do ácido dinitrosalicúlico (MILLER, 1959) e o dióxido de enxofre total conforme Pearson (1976). O teor de sólidos solúveis totais das amostras foi determinado por refratometria (INSTITUTO ADOLFO LUTZ, 1985). A cor da polpa foi determinada por meio de leituras diretas realizadas em colorímetro MINOLTA, modelo CR300, com valores expressos em L*.

As análises microbiológicas dos produtos foram realizadas segundo Downes \& Ito (2001) e Silva et al. (2001).

A avaliação sensorial da polpa foi feita por meio do teste de aceitação global, do néctar elaborado a partir das mesmas, utilizando-se de uma escala hedônica estruturada de 9 pontos, onde 1 representava a nota mínima (desgostei muitíssimo) e 9 a nota máxima (gostei muitíssimo), aplicada a 30 provadores não treinados (MONTEIRO, 1984).

$\mathrm{O}$ experimento foi conduzido em delineamento inteiramente casualizado (DIC), em esquema fatorial 3 x 5 (tratamentos $\mathrm{x}$ tempo de armazenamento) com três repetição. Os dados foram submetidos a análises de regressão polinomial de modelos linar, quadrático e cúbico. O critério para a escolha do modelo foi definido através da significância do teste $\mathrm{F}$ a $5 \%$ de probabilidade e do maior valor de coeficiente de determinação $\left(\mathrm{R}^{2}\right)$, sendo este mínimo de 0,70 para a utilização das curvas. Quando as regressões não foram significativas para todos os tratamentos, aplicou-se o teste de Tukey para comparação de médias dos tratamentos, empregando-se o programa estatístico Fundação Arthur Bernardes (2003).

Ciênc. agrotec., Lavras, v. 30, n. 4, p. 715-723, jul./ago., 2006 


\section{RESULTADOS E DISCUSSÃO}

$\mathrm{Na}$ Tabela 1, apresenta-se um resumo das análises de regressões.

Não observou-se variação significativa $(\mathrm{p}>0,05)$ da acidez total titulável para nenhum dos tratamentos ao longo do armazenamento, como pode ser observado através da análise de regressão na Tabela 1 e Figura 1. Assim, estudou-se o efeito do tratamento pelo teste de Tukey para comparação das médias (Tabela 2).

Para o pH, observou-se uma diminuição ao longo do armazenamento para os três tratamentos (Figura 2).

Através da Tabela 1, verifica-se que o tratamento Controle, sem adição de sacarose, foi o único que não teve alteração no teor de sólidos solúveis totais com o decorrer do tempo de armazenamento (Figura 3). Verifica-se também, que o teor de sólidos solúveis totais dos produtos obtidos pelos tratamentos com $17,4 \%(\mathrm{p} / \mathrm{p})$ de sacarose e com $28,65 \%$ de $(\mathrm{p} / \mathrm{p})$ sacarose está relacionado com a concentração de sacarose adicionada durante a formulação dos mesmos.

Os valores de açúcares redutores mostraram uma tendência de crescimento ao longo do tempo de armazenamento (Figura 4), para todos os tratamentos, devido à acidez do meio propiciar a hidrólise da sacarose levando a formação de glicose e frutose (açúcares redutores). Além disso, o tempo de armazenagem deve influenciar na hidrólise da sacarose, visto que a maior concentração de açúcares redutores coincidiu com o maior período de estocagem. Observa-se ainda, que o tratamento com $28,6 \%$ (p/p) de sacarose alcançou os maiores valores de açúcares redutores entre todos os tratamentos, em virtude do aumento da concentração inicial de sacarose.

TABELA 1 - Resumo das análises das variâncias das regressões polinomiais para as determinações físico-químicas e análise sensorial de polpas de bacuri submetidas a diferentes tratamentos, preservadas por métodos combinados.

\begin{tabular}{|c|c|c|c|c|c|c|}
\hline \multirow[b]{3}{*}{ Determinacão } & \multicolumn{6}{|c|}{ Tratamentos } \\
\hline & \multicolumn{2}{|c|}{ Controle } & \multicolumn{2}{|c|}{$17,4 \%(p / p)$ de sacarose } & \multicolumn{2}{|c|}{$28,6 \%(p / p)$ de sacarose } \\
\hline & GL & $\mathbf{Q M}$ & GL & $\mathbf{Q M}$ & GL & QM \\
\hline ATT & 3 & $0,002438^{\mathrm{NS}}$ & 2 & $0,001877^{\mathrm{NS}}$ & 2 & $0,00242^{\mathrm{NS}}$ \\
\hline $\mathrm{pH}$ & 2 & $0,0370,714 *$ & 1 & $0,07396^{*}$ & 1 & $0,07569 *$ \\
\hline SST & 1 & $1,196000^{\mathrm{NS}}$ & 1 & $0,88209 *$ & 1 & $2,33289 *$ \\
\hline AR & 1 & $1,459240 *$ & 1 & $162,9737 *$ & 1 & $356,4090 *$ \\
\hline Aa & 3 & $0,000009047^{\mathrm{NS}}$ & 2 & $0,00002134 *$ & 2 & $0,0001054 *$ \\
\hline $\mathrm{SO}_{2}$ & 2 & $30504,52 *$ & 1 & $50777,03 *$ & 3 & $18572,06^{*}$ \\
\hline Cor (valor L*) & 1 & $7,34449^{\mathrm{NS}}$ & 1 & $3,45744^{\mathrm{NS}}$ & 1 & $14,06596 *$ \\
\hline Avaliação global & 1 & $0,65025^{\mathrm{NS}}$ & 1 & $0,08281^{\mathrm{NS}}$ & 2 & $0,33128^{\mathrm{NS}}$ \\
\hline
\end{tabular}

ATT - Acidez total titulável, SST - Sólidos solúveis totais, AR - Açúcares redutores, Aa - Atividade de água, $\mathrm{SO}_{2}-$ Dióxido de enxofre

* Significativo ao nível de 5\% de probabilidade $(\mathrm{P} \leq 0,05)$; NS - Não-Significativo ao nível de 5\% de probabilidade (P>0,05).

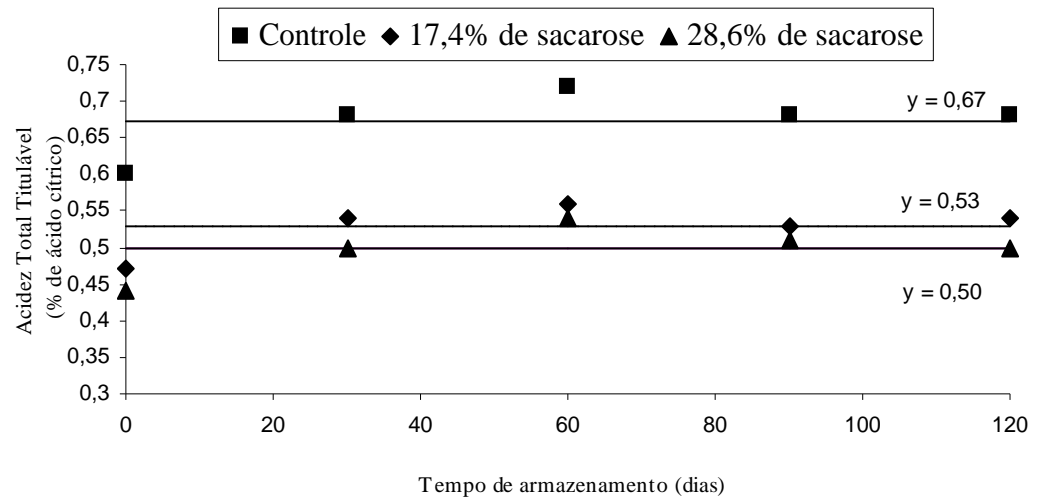

FIGURA 1 -Acidez total titulável de polpas de bacuri submetidas a diferentes tratamentos, preservadas por métodos combinados em função do tempo de armazenamento. 
TABELA 2 - Resultados médios de acidez total titulável de polpas de bacuri submetidas a diferentes tratamentos, preservadas por métodos combinados.

\begin{tabular}{lcc}
\hline Tratamento & Médias* $^{*}$ & Desvio Padrão \\
\hline Controle & $0,67^{\mathrm{a}}$ & 0,04 \\
$17,4 \%(\mathrm{p} / \mathrm{p})$ de Sacarose & $0,53^{\mathrm{b}}$ & 0,03 \\
$28,6 \%(\mathrm{p} / \mathrm{p})$ de Sacarose & $0,50^{\mathrm{b}}$ & 0,04 \\
\hline
\end{tabular}

*Médias seguidas pela mesma letra não diferem entre si, pelo teste de Tukey, ao nível de 5\% de probabilidade (P>0,05).

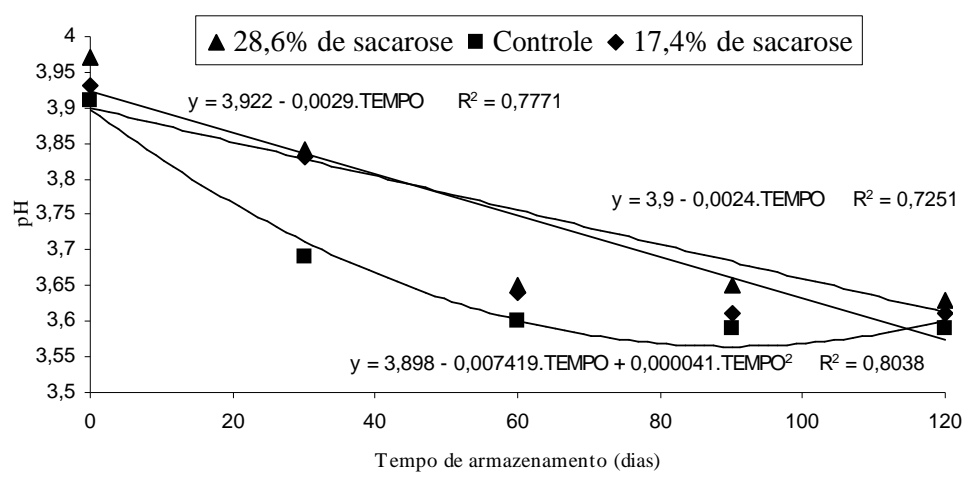

FIGURA $2-\mathrm{pH}$ de polpas de bacuri submetidas a diferentes tratamentos, preservadas por métodos combinados em função do tempo de armazenamento.

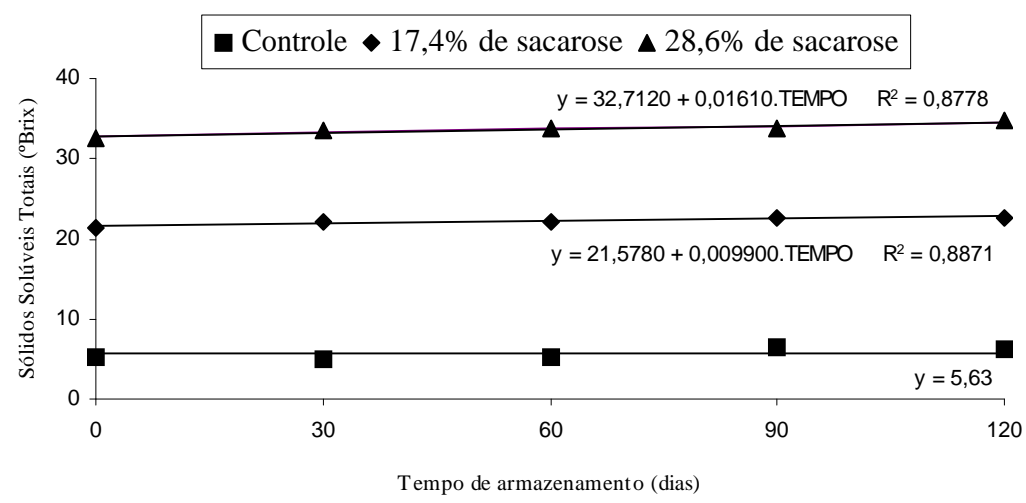

FIGURA 3 - Teor de sólidos solúveis totais de polpas de bacuri submetidas a diferentes tratamentos, preservadas por métodos combinados em função do tempo de armazenamento.

Ciênc. agrotec., Lavras, v. 30, n. 4, p. 715-723, jul./ago., 2006 
Na Figura 5, observa-se que o tratamento com $28,6 \%(\mathrm{p} / \mathrm{p})$ de sacarose apresentou o maior decréscimo da atividade de água, como consequiência do aumento da quantidade de açúcares redutores pela hidrólise da sacarose. Segundo Alexandre et al. (2004), a hidrólise ácida da sacarose, que produz glicose e frutose, provoca o aumento da quantidade de açúcares redutores que conseqüentemente aumenta o número de moles de soluto, fato que explicaria também a redução da atividade de água durante o armazenamento. $\mathrm{O}$ tratamento Controle não apresentou variação durante o armazenamento, o que pode ser explicado pela não adição de sacarose, como foi feita nos outros dois tratamentos. $\mathrm{O}$ menor valor de atividade de água alcançado durante os quatro meses de armazenamento foi de 0,951 (tratamento com $28,6 \%(\mathrm{p} / \mathrm{p}$ ) de sacarose). Portanto, todos os produtos obtidos podem ser considerados alimentos de alta umidade, pois apresentaram valores de atividade de água superiores a 0,90 (AGUILERA \& CHIRIFE, 1994). De acordo com Alexandre et al. (2004) e Alzamora (1997), o crescimento microbiano não é inibido somente por esta redução da atividade de água. Portanto, a utilização de outros fatores para prolongar a vida de prateleira da polpa de bacuri foi necessária.

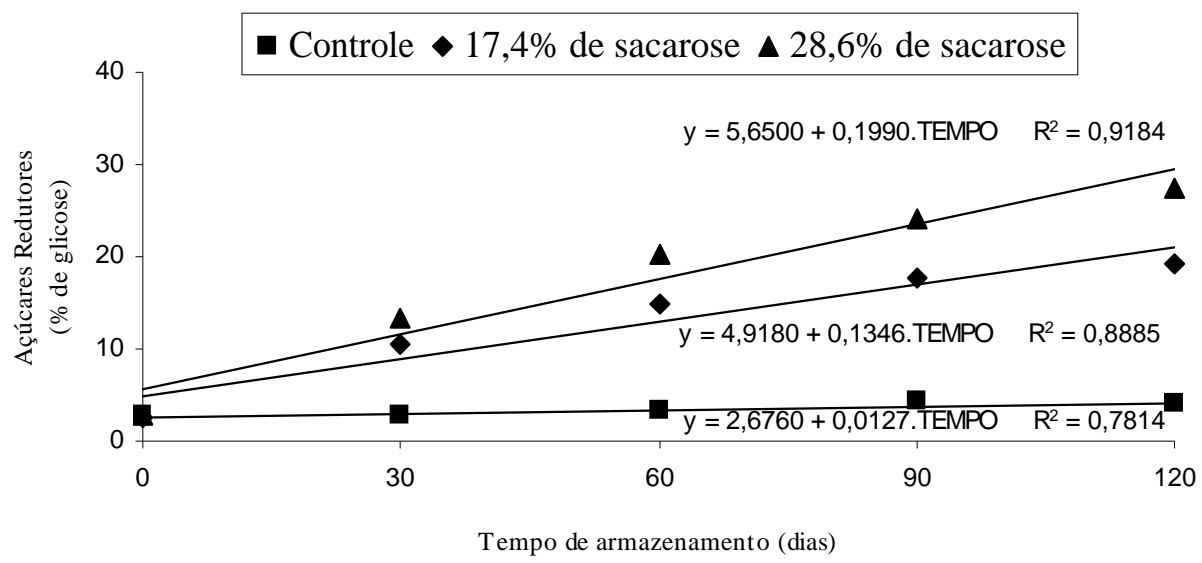

FIGURA 4 - Teor de açúcares redutores de polpas de bacuri submetidas a diferentes tratamentos, preservadas por métodos combinados em função do tempo de armazenamento.

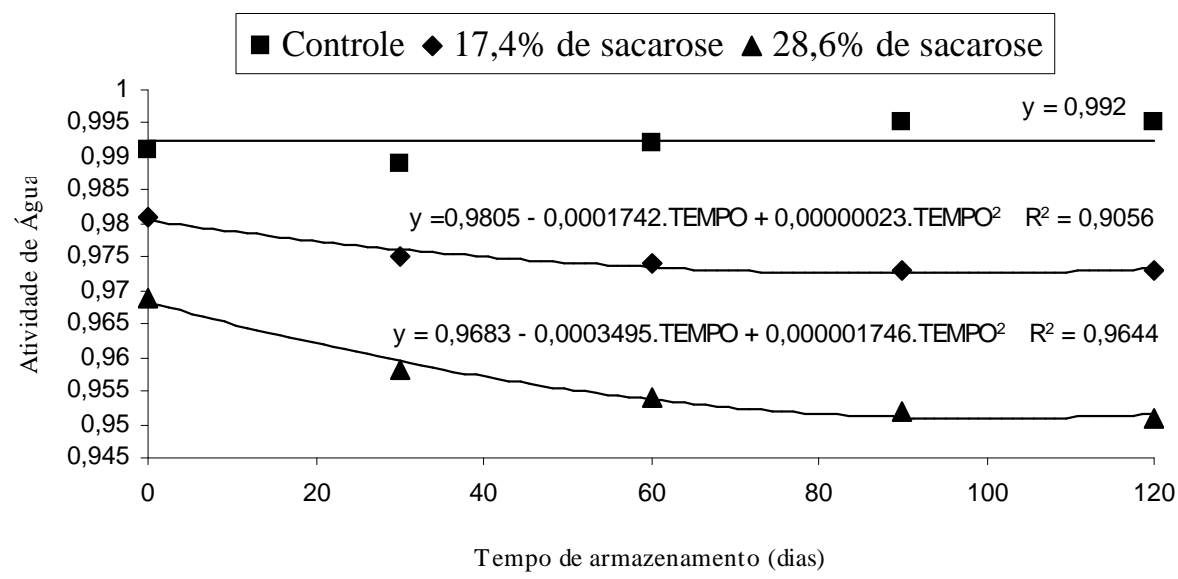

FIGURA 5 - Atividade de água (Aa) de polpas de bacuri submetidas a diferentes tratamentos, preservadas por métodos combinados em função do tempo de armazenamento. 
Os resultados obtidos para o dióxido de enxofre total $\left(\mathrm{SO}_{2}\right)$, em todos os tratamentos, mostraram que ocorreu uma perda de $\mathrm{SO}_{2}$ ao longo dos quatro meses de armazenamento (Figura 6). Para todos os tratamentos, pode-se considerar uma perda média de $85 \%$ de $\mathrm{SO}_{2}$ no decorrer do armazenamento, mostrando a influência do tempo no processo de degradação desse aditivo. A perda de $\mathrm{SO}_{2}$ durante o armazenamento pode estar relacionada com a permeabilidade da embalagem quanto ao oxigênio e à luz, condições de armazenagem e características do produto. De acordo com Pina et al. (2003), a estabilidade do $\mathrm{SO}_{2}$ depende grandemente da natureza química do alimento, da severidade do processo e do tempo e condições de estocagem. Mesquita et al. (2003) observaram durante a vida de prateleira do pedúnculo de caju preservado por métodos combinados que a perda de $\mathrm{SO}_{2}$ ocorre, principalmente, devido à oxidação e combinação irreversível dos sulfitos com os constituintes dos alimentos.

Os valores obtidos para cor (Figura 7) indicaram maior tendência ao escurecimento (redução de $\mathrm{L}^{*}$ ) com o tempo de armazenamento para o tratamento com 28,6\% (p/ p) de sacarose, devido à presença de maiores quantidades de sacarose. Alexandre et al. (2004) observaram durante a conservação do açaí pela tecnologia de obstáculos que a adição de sacarose afetou significativamente $\mathrm{L}^{*}$, que diminuiu com o aumento da concentração de sacarose em relação ao fruto in natura.

\section{Controle $\bullet 17,4 \%$ de sacarose $\wedge 28,6 \%$ de sacarose}

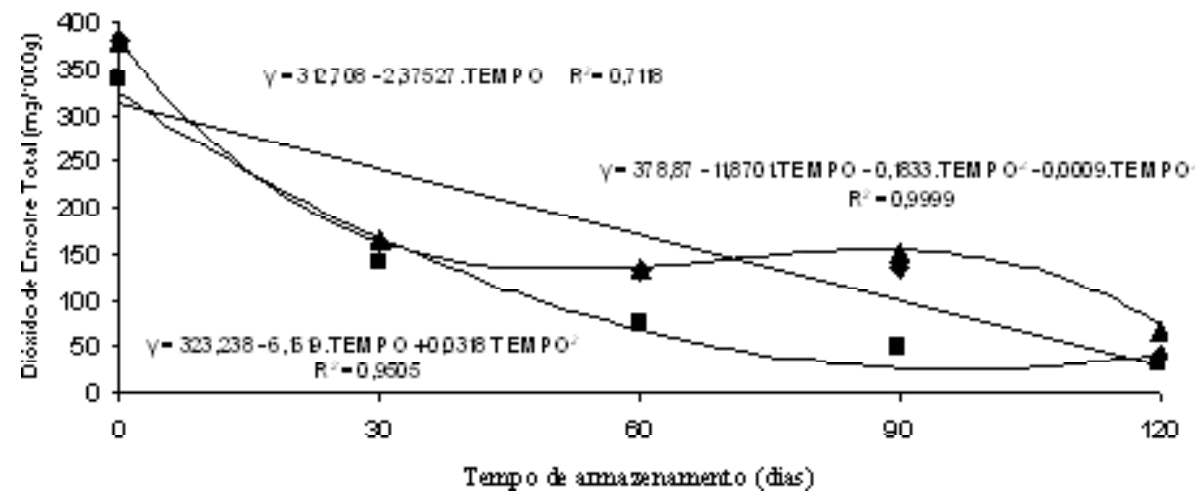

FIGURA 6 - Teor de $\mathrm{SO}_{2}$ de polpas de bacuri submetidas a diferentes tratamentos, preservadas por métodos combinados em função do tempo de armazenamento.

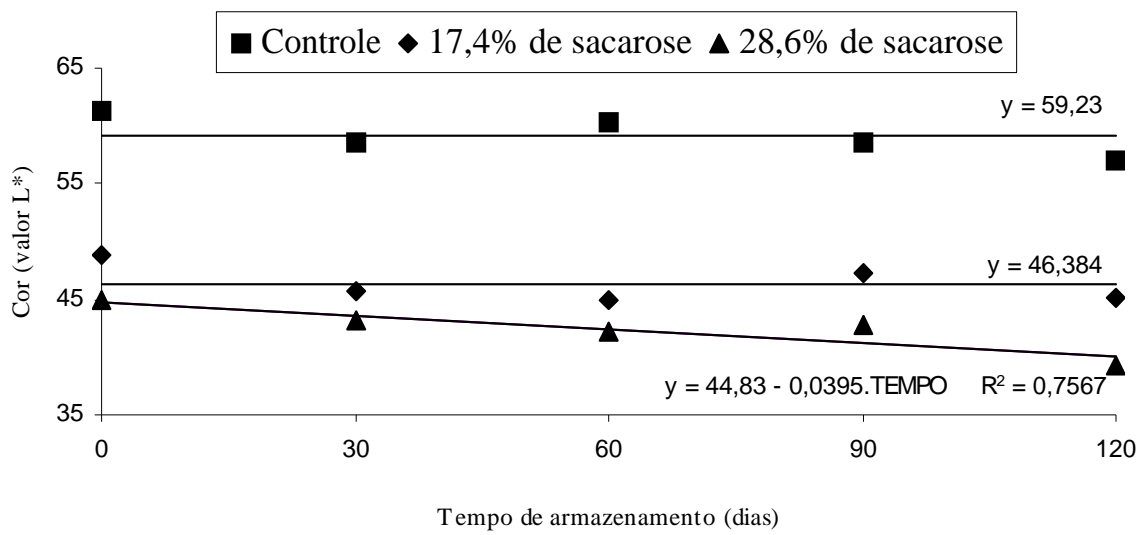

FIGURA 7 - Cor (valor de $\mathrm{L}^{*}$ ) de polpas de bacuri submetidas a diferentes tratamentos, preservadas por métodos combinados em função do tempo de armazenamento.

Ciênc. agrotec., Lavras, v. 30, n. 4, p. 715-723, jul./ago., 2006 
Os produtos obtidos, nos três tratamentos, logo após o processamento e em todos os tempos de armazenamento avaliados, apresentaram contagens de bolores e leveduras inferiores a $100 \mathrm{UFC} / \mathrm{g}$ e coliformes a $35^{\circ} \mathrm{C}$ e a $45^{\circ} \mathrm{C}$ inferiores a $3 \mathrm{NMP} / \mathrm{g}$. A ocorrência de Salmonella sp. não foi detectada em nenhuma das amostras analisadas. Entretanto, foram encontrados valores de microrganismos aeróbios mesófilos nos produtos recém processados e com 30 dias de armazenamento, para todos os tratamentos (Tabela 3). Embora não existam na Legislação brasileira padrões para microrganismos aeróbios mesófilos e coliformes a $35^{\circ} \mathrm{C}$, de forma geral, é preconizado que alimentos contendo contagens microbianas da ordem de $10^{5}-10^{6} \mathrm{UFC} / \mathrm{g}$ são impróprios para o consumo humano, devido à perda do valor nutricional, alterações sensoriais, riscos de deterioração e/ou presença de patógenos (ARRUDA, 2002), sendo que esses valores não foram encontrados em

TABELA 3 - Médias dos resultados das análises microbiológicas das amostras de polpas de bacuri submetidas a diferentes tratamentos, preservadas por métodos combinados durante 120 dias de armazenamento à temperatura ambiente.

\begin{tabular}{|c|c|c|c|c|c|}
\hline \multirow{3}{*}{ Análises } & \multicolumn{4}{|c|}{ Tratamento Controle } & \\
\hline & \multicolumn{5}{|c|}{ Tempo (dias) } \\
\hline & 0 & 30 & 60 & 90 & 120 \\
\hline $\begin{array}{l}\text { Microrganismos aeróbios mesófilos } \\
\text { (UFC/g) }\end{array}$ & $5,6 \times 10^{2}$ & $3,6 \times 10^{2}$ & $<10$ & $<10$ & $<10$ \\
\hline Bolores e Leveduras (UFC/g) & $<100$ & $<100$ & $<100$ & $<100$ & $<100$ \\
\hline Coliformes a $35^{\circ} \mathrm{C}(\mathrm{NMP} / \mathrm{g})$ & $<3$ & $<3$ & $<3$ & $<3$ & $<3$ \\
\hline Coliformes a $45^{\circ} \mathrm{C}(\mathrm{NMP} / \mathrm{g})$ & $<3$ & $<3$ & $<3$ & $<3$ & $<3$ \\
\hline \multirow[t]{2}{*}{ Salmonella sp. } & $*$ & $*$ & $*$ & $*$ & $*$ \\
\hline & \multicolumn{5}{|c|}{ Tratamento com $17,4 \%$ (p/p) de sacarose } \\
\hline \multirow{2}{*}{ Análises } & \multicolumn{5}{|c|}{ Tempo (dias) } \\
\hline & 0 & 30 & 60 & 90 & 120 \\
\hline $\begin{array}{l}\text { Microrganismos aeróbios mesófilos } \\
\text { (UFC/g) }\end{array}$ & $4,4 \times 10^{2}$ & $2,3 \times 10^{2}$ & $<10$ & $<10$ & $<10$ \\
\hline Bolores e Leveduras (UFC/g) & $<100$ & $<100$ & $<100$ & $<100$ & $<100$ \\
\hline Coliformes a $35^{\circ} \mathrm{C}(\mathrm{NMP} / \mathrm{g})$ & $<3$ & $<3$ & $<3$ & $<3$ & $<3$ \\
\hline Coliformes a $45^{\circ} \mathrm{C}(\mathrm{NMP} / \mathrm{g})$ & $<3$ & $<3$ & $<3$ & $<3$ & $<3$ \\
\hline \multirow[t]{2}{*}{ Salmonella sp. } & $*$ & $*$ & $*$ & $*$ & $*$ \\
\hline & \multicolumn{5}{|c|}{ Tratamento com $28,6 \%(p / p)$ de sacarose } \\
\hline \multirow{2}{*}{ Análises } & \multicolumn{5}{|c|}{ Tempo (dias) } \\
\hline & 0 & 30 & 60 & 90 & 120 \\
\hline $\begin{array}{l}\text { Microrganismos aeróbios mesófilos } \\
\text { (UFC/g) }\end{array}$ & $5,7 \times 10^{2}$ & $3,5 \times 10^{1}$ & $<10$ & $<10$ & $<10$ \\
\hline Bolores e Leveduras (UFC/g) & $<100$ & $<100$ & $<100$ & $<100$ & $<100$ \\
\hline Coliformes a $35^{\circ} \mathrm{C}(\mathrm{NMP} / \mathrm{g})$ & $<3$ & $<3$ & $<3$ & $<3$ & $<3$ \\
\hline Coliformes a $45^{\circ} \mathrm{C}(\mathrm{NMP} / \mathrm{g})$ & $<3$ & $<3$ & $<3$ & $<3$ & $<3$ \\
\hline Salmonella sp. & $*$ & $*$ & $*$ & $*$ & $*$ \\
\hline
\end{tabular}


nenhuma das amostras analisadas. Portanto, os produtos obtidos atenderam aos padrões microbiológicos estabelecidos pela legislação vigente no País (BRASIL, 2001), que estabelece os seguintes padrões microbiológicos sanitários para a polpa de fruta: coliformes a $45^{\circ} \mathrm{C}$, máximo $10^{2} \mathrm{NMP} / \mathrm{g}$ e ausência de Salmonella sp. em $25 \mathrm{~g}$ do produto.

Os resultados referentes à avaliação microbiológica mostraram que as contagens microbianas foram semelhantes nos três tratamentos (Tabela 3). Estes resultados indicam que os tipos de obstáculos utilizados (redução da atividade de água, tratamento térmico brando, adição de benzoato de sódio e metabissulfito de sódio) e suas intensidades foram capazes de assegurar a estabilidade microbiológica dos produtos, durante os 120 dias de armazenamento, à temperatura ambiente. Um estudo de conservação de mamão por métodos combinados mostrou que, após a estabilização, os níveis de carga microbiana (contagem de microrganismos aeróbios mesófilos, bolores e leveduras) se apresentaram muito abaixo do nível de detecção (LOPEZ-MALO et al., 1994).

Não se observou variação significativa $(p>0,05)$ para os valores médios de aceitação global durante o armazenamento (Tabela 1), que se situaram próximos de 6,0 , o que corresponde na escala hedônica ao termo "gostei ligeiramente". Assim, estudou-se o efeito do tratamento pelo teste de Tukey para comparação das médias (Tabela 4), não observando diferença significativa $(P \leq 0,05)$ entre os tratamentos, sendo a média entre os tratamentos de 6,3, ficando entre os termos hedônicos "gostei moderadamente" e "gostei ligeiramente".

Segundo Labuza \& Schimdl (1988), o final da vida útil de um produto pode ser considerado quando há uma queda de 1,5 pontos na escala hedônica, o que não ocorreu com os produtos durante o armazenamento. Isto indica que os produtos podem ser considerados como aceitáveis pelos consumidores, por todo o tempo de vida de prateleira estudado.

TABELA 4 - Resultados médios de avaliação global de néctares elaborados a partir de polpas de bacuri submetidas a diferentes tratamentos, preservadas por métodos combinados durante 120 dias de armazenamento à temperatura ambiente.

\begin{tabular}{lcc}
\hline Tratamento & Médias* $^{*}$ & Desvio Padrão \\
\hline Controle & $6,13^{\mathrm{a}}$ & 0,77 \\
$17,4 \%(\mathrm{p} / \mathrm{p})$ de Sacarose & $6,42^{\text {a }}$ & 0,53 \\
$28,6 \%(\mathrm{p} / \mathrm{p})$ de Sacarose & $6,40^{\mathrm{a}}$ & 0,54 \\
\hline
\end{tabular}

* Médias seguidas pela mesma letra não diferem entre si, pelo teste de Tukey, ao nível de 5\% de probabilidade (P>0,05).

\section{CONCLUSÕES}

As características físico-químicas dos produtos obtidos sofreram pouca alteração durante o armazenamento, sendo os açúcares redutores e o teor de dióxido de enxofre as características mais afetadas nos três produtos. A perda de dióxido de enxofre foi considerada elevada (cerca de $85 \%$ ) ao longo do tempo de armazenamento.

A polpa de bacuri conservada por métodos combinados apresentou estabilidade microbiológica por, no mínimo, 120 dias à temperatura ambiente para todos os tratamentos. A avaliação sensorial mostrou que os produtos, independentemente do tratamento utilizado, tiveram boa aceitabilidade durante o período de armazenamento.

A preservação da polpa de bacuri pela aplicação de métodos combinados mostrou ser uma alternativa capaz de contribuir para a redução das perdas pós-colheita de fruta e estender a vida de prateleira da polpa, utilizando-se poucos obstáculos que assegurem a estabilidade microbiológica e sensorial do produto final, independente da adição ou não de sacarose, nas concentrações estudadas $(0 \%, 17,4 \%$ e $28,6 \%(\mathrm{p} / \mathrm{p}))$.

\section{REFERÊNCIAS BIBLIOGRÁFICAS}

AGUILERA, J. M.; CHIRIFE, J. Combined methods for the preservation of foods in latin América and the CYTED-D Project. Journal of Food Engineering, London, v. 22, n. 1/ 4, p. 433-444, 1994.

ALEXANDRE, D.; CUNHA, R. L.; HUBINGER, M. D. Conservação do açaí pela tecnologia de obstáculos. Ciência e Tecnologia de Alimentos, Campinas, v. 24, n. 1, p. 114-119, 2004.

ALZAMORA, S. M. Preservación I: alimentos conservados por fatores combinados. In: AGUILERA, J. M. Temas em tecnologia de alimentos. México: Instituto Politécnico Nacional, 1997. p. 45-88.

ALZAMORA, S. M.; TAPIA, M. S.; ARGAIZ, A.; WELTI, J. Application of combined methods technology in minimally processed fruits. Food Research International, London, v. 26, n. 2, p. 125-130, 1993.

ARRUDA, M. C. Processamento mínimo de melão rendilhado: tipo de corte, temperatura de armazenamento e atmosfera modificada. 2002. 69 f. Dissertação (Mestrado em Agronomia) - Escola Superior de Agricultura "Luiz de Queiroz", Piracicaba, 2002. 
BEZERRA, G. A. S.; MAIA, G. A.; FIGUEIREDO, R. W. de; GOMES, A. M. M.; SOUZA FILHO, M. de S. M. de. Influência da redução da atividade de água, adição de conservantes e braqueamento na preservação da polpa de bacuri por métodos combinados. Boletim CEPPA, Curitiba, v. 22, n. 2, p. 217-232, 2004.

BRASIL. Resolução R.D.C. ${ }^{\circ}$ 12, de 2 de janeiro de 2001. Dispõe sobre os princípios gerais para o estabelecimento de critérios e padrões microbiológicos para alimentos. Diário Oficial da União, Brasília, 2001.

CHIRIFE, J.; FAVETO, G. J. Some physico-chemical basis of food preservation by combined methods. Food Research international, London, v. 25, n. 5, p. 389-396, 1992.

CLEMENT, C. R.; VENTURIERI, G. A. Bacuri and cupuassu. In: NAGY, S.; SHAW, P. E.; WARDOWSKI, W. Fruits of tropical and subtropical origin: composition, properties, uses. Flórida: Science Source, 1990. p. 178-192.

DAZA, M. S.; VILLEGAS, Y.; MARTINEX, A. Minimal water activity for growth of listeria monocytogenes as affected by solute and temperature. International Journal Microbiological, London, v. 14, p. 333-337, 1997.

DOWNES, F. P.; ITO, K. Compendium of methods for the microbiological examination of foods. 4. ed. Washington: American Public Health Association, 2001. 676 p.

FONDERFRU. Estudo de comercialização de frutas frescas a nível nacional. Caracas: Fondo de Desarrollo Fruticolo, 1986. 65 p.

FUNDAÇÃO ARTHUR BERNARDES. Sistema para análises estatísticas. Versão 8.1. Viçosa, 2003.

INSTITUTO ADOLFO LUTZ. Normas analíticas do Instituto Adolfo Lutz: métodos químicos e físicos para análises de alimentos. 3. ed. São Paulo, 1985. v. 1, 533 p.

LABUZA, T. P.; SCHIMDL, M. K. Use of sensory data in the shelf life testing of foods: principles and graphical methods for evaluation. Cereals Foods World, Saint Paul, v. 33, n. 2, p. 193-206, 1988.
LEISTNER, L. Food preservation by combined methods. Food Research International, London, v. 25, n. 2, p. 151158, 1992.

LOPEZ-MALO, A.; PALOU, E.; WELTI, J.; CORTEZ, P.; ARGAIZ, A. Shelf stable high moisture papaya minimally processed by combined methods. Food Research International, London, v. 27, n. 5, p. 545553, 1994.

MESQUITA, P. C.; MAIA, G. A.; SOUZA FILHO, M. S. M.; NASSU, R. T. Estabilidade microbiológica, físico-química e sensorial de pedúnculos de caju (Anacardium occidentale L.) processados por métodos combinados. Ciência e Tecnologia de Alimentos, Campinas, v. 23, n. 3, p. 366-369, 2003.

MILLER, G. L. Use of dinitro acid reagent for determination of reducing sugars. Analytical Chemistry, Washington, n. 31, p. 226-248, 1959.

MONTEIRO, C. B. L. Técnicas de avaliação sensorial. 2. ed. Curitiba: UFPR/CEPPA, 1984. 101 p.

PEARSON, D. Técnicas de laboratorio para el analisis de alimentos. Zaragoza: Acribia, 1976. 331 p.

PINA, M. G. M.; MAIA, G. A.; SOUZA FILHO, M. S. M.; FIGUEIREDO, R. W.; MONTEIRO, J. C. S. Processamento e conservação de manga por métodos combinados. Revista Brasileira de Fruticultura, Jaboticabal, v. 25, n. 1, p. 6366, 2003.

SILVA, N.; JUNQUEIRA, V. C. A.; SILVEIRA, N. F. A. Manual de métodos de análise microbiológica de alimentos. 2. ed. São Paulo: Varela, 2001. 229 p.

VILLACHICA, H. Frutales y hortalizas promisorios de la Amazonia. Lima: TCA, 1996.

WELTI-CHANES, J.; VERGARA-BALDERAS, F.; LOPEZMALO, A. Minimally processed foods: state of art and future. In: FITO, P.; ORTEGA-RODRIGUEZ, E.; BARBOSACANOVAS, G. V. Food engineering 2000. New York: Chapman \& Hall, 1997. p. 181-212. 